\title{
Povos indígenas e o direito à terra na realidade brasileira
}

\section{Indigenous peoples and the right to land in Brazilian reality}

\author{
Elizângela Cardoso de Araújo Silvaa
}

Resumo: Este artigo analisa o processo histórico das afirmações legais do direito dos povos indígenas brasileiros à terra. Trata da violência contra os povos originários: expropriação e mortes dos que resistem e lutam pela garantia do acesso e usufruto dos bens naturais. Com base na pesquisa bibliográfica e documental, analisam-se os conflitos que atingem os povos indígenas e a concreta necessidade de demarcação como condição fundamental para a continuidade da vida indígena na realidade brasileira.

Palavras-chave: Indígena. Terra. Direitos humanos.
Abstract: This article deals with the historical process of the legal affirmations of the right of Brazilian indigenous peoples to land. It deals with the violence against indigenous peoples: expropriation and deaths of those who resist and fight for the guarantee of access and usufruct of natural goods. Based on bibliographical and documentary research, it analyzes conflicts that affect indigenous peoples and the concrete need for demarcation as a fundamental condition for the continuity of indigenous life in the Brazilian reality.

Keywords: Indigenous. Land. Human rights.

\section{Introdução}

análise do processo histórico da luta e conquista do direito dos
povos indígenas à terra na sociabilidade capitalista exige uma
breve caracterização da relação entre instâncias de poder e povos

andígena Pankararu. Universidade Federal de Pernambuco (UFPE), Pernambuco-RE, Brasil. 
violências sofridas por indígenas em conflitos diretos com a classe burguesa de ruralistas, donos do agronegócio acarretando consequências nefastas para os povos que ainda vivem no campo.

A invasão, ocupação e exploração do solo brasileiro foram e são determinantes para as transformações radicais que os povos originários passam no decorrer de cinco séculos. Um longo processo de devastação física e cultural eliminou grupos gigantescos e inúmeras etnias indígenas, especialmente através do rompimento histórico entre os índios e a terra. Por dentro da tradição da teoria social crítica, podemos captar elementos teórico-metodológicos muito significativos para análise do processo histórico social vivido por esses povos e apreender a teia contemporânea de ameaças à própria continuidade da existência da vida indígena e sua possibilidade de autodeterminação e auto-organização.

Destaca-se a importância de reconhecer as mudanças que ocorrem com a interação real entre a vida indígena no campo brasileiro (marcada por elementos singulares de ruralidade) e o compartilhamento de diversos elementos próprios da vida tipicamente capitalista em algumas regiões brasileiras (os processos de proletarização e assalariamento indígena, incorporação de tecnologia na vida cotidiana e na organização do trabalho).

Esse destaque tem o intuito de enfatizar a necessidade da superação de um pensamento evolucionista que defende a integração e a assimilação obrigatória dos povos indígenas ao modo de vida tipicamente capitalista na expectativa do apagamento étnico. Considera-se neste texto que essas transformações vividas por indígenas brasileiros não apagaram os traços étnicos que unem socialmente os grupos indígenas. As formas específicas de organização social estão presentes em elementos que dão unidade inter e intraétnica de diversas expressões da cultura do trabalho, organização econômica, social e vivências espirituais.

No caso específico do Brasil, de acordo com dados da Fundação Nacional do Índio, Funai (dados do censo do IBGE - Instituto Brasileiro de Geografia e Estatística, 2010 disponíveis no site da FUNAI, 2016), contabiliza-se aproximadamente 305 etnias de povos indígenas, preservando 274 
línguas e totalizando 896,9 mil indígenas distribuídos em todo o território brasileiro em 688 terras e áreas urbanas. ${ }^{1}$

A condição dos povos indígenas na realidade brasileira foi histórica e socialmente desprezada ou tratada com muito preconceito e violência. $\mathrm{O}$ próprio termo "índio" não tem unidade concreta, nem semântica, expressando a marca histórica contraditória da colonização. A diversidade dos grupos étnico-linguísticos da América Latina não cabe nesse termo genérico, porém ele passa a ser assumido historicamente como uma definição estratégica de um grupo social no processo geral de organização e reivindicação política.

De acordo com Almeida (2010, p. 31), “em toda a América havia inúmeros povos distintos que foram chamados de índios pelos europeus que aqui chegaram", classificados pelos portugueses com o intuito de viabilizar os objetivos da colonização. Nas investidas etnocêntricas, o colonizador era a referência. Assim, os nativos foram classificados em dois grupos de índios: "aliados" e "inimigos".

Por dentro da reprodução histórica de preconceitos e de toda forma de violência da escravidão, perseguições e catequização, a trajetória institucional da atuação dos órgãos de "proteção" também registrou a diversidade de formas de organização social e resistência dos povos originários - língua, tipo físico e cultura - , constatando a diversidade de troncos linguísticos indígenas divididos em inúmeros subgrupos.

A primeira parte do artigo apresenta elementos históricos da condição social em que viveram e vivem os povos indígenas brasileiros. A segunda parte versa sobre os avanços legais da proteção das terras indígenas e as contradições da demarcação de terras indígenas na sociedade capitalista. Conclui-se com reflexões sobre a questão da importância da luta em defesa dos direitos humanos indígenas e sobre os limites da emancipação política indígena na sociabilidade burguesa.

1. De acordo com a Funai (2016), existem 32 grupos não contatados (isolados) confirmados pelo órgão (Disponível em: <http://www.funai.gov.br/index.php/nossas-acoes/politica-indigenista?start=4>. Acesso em: set. 2016). 


\section{Histórica questão fundiária no Brasil: expropriação de terra indígena, aldeamento e avanços da política indigenista}

Muitas são as formas históricas de acesso, uso e apropriação da terra. Esses são processos que geram diversos conflitos na história da humanidade. No caso específico da realidade brasileira, a terra, na sua dimensão política e econômica, é um bem que envolve muitas tensões e conflitos de disputa. Por se tratar de um meio de produção de riqueza bastante valioso, dispondo de diferentes possibilidades de exploração, o seu acesso, uso e apropriação são desiguais, envolvendo violência institucional, material e estratégias políticas que promovem concentração e expropriação. Trata-se aqui da constituição do latifúndio.

A realidade do acesso, uso e apropriação das terras brasileiras é resultado de uma condição colonial de longa exploração. É importante recordar as consequências nocivas do sistema colonial secular que, além de devastar física e culturalmente as populações originárias, também garantiu a instituição das grandes propriedades privadas nas mãos de poucos. Referimo-nos à grande concentração de terras nas mãos de classes agrárias que exerceram seu violento poder de dominação e exploração dos trabalhadores do campo através de múltiplas formas de expropriação.

A Lei de Terras de 1850 foi o "batismo do latifúndio". Depois do longo processo de concessões do sistema de sesmarias, através do qual a Coroa portuguesa atribuía o poder de exploração de determinadas extensões de terras a sesmeiros com vistas à produção, a referida lei condiciona o acesso à terra exclusivamente por meio da compra. Nesse contexto também se alargou a grilagem, caracterizada pela falsificação em larga escala de documentações de posse de terra. ${ }^{2}$

A legitimação do latifúndio no Brasil é marcado por estratégias (i)legais e políticas que favoreceram economicamente as classes dominantes no meio agrário até os dias atuais. É também a base da violência social, desagregação,

2. "Terras griladas são aquelas que foram apropriadas ilegalmente, através da falsificação de documentos. A grilagem, [é uma] [...] prática arraigada na história agrária brasileira” (Caldart et al., 2012, p. 441). 
desaldeamento e superexploração das massas pobres trabalhadoras do campo, indígenas e negras do nosso país.

É com o avanço das formas capitalistas de exploração do campo brasileiro que a relação entre indígenas, lavradores, quilombolas vive constantes ameaças de expropriação e reprodução das formas de rompimento com seu principal meio de reprodução da vida: a terra. Temos inúmeros casos na realidade brasileira de expulsão de populações ribeirinhas, tradicionais, quilombolas, pesqueiras pela ação predatória do grande capital nas investidas dos grandes empreendimentos (hidrelétricas, barragens, exploração de minérios, de madeira, entre tantos outros).

Dos primeiros anos da colonização até a Lei de Terras (séculos XV-XIX) ocorre uma destruição radical das populações originárias, bem como a dispersão e diversas formas de migrações compulsórias, produto da expulsão de seus territórios. A Lei de Terras exerceu a função de institucionalizar formas de expropriações. Os povos que resistiram e adentraram os sertões e outras regiões de difícil acesso no país, durante o século XX, continuam ameaçados com os avanços de formas de exploração capitalista no campo. Os processos constantes de expulsão de indígenas leva-os a compor uma massa de trabalhadores espoliados e em condições de extrema precariedade, seja nas pequenas ou nas grandes cidades.

Com o avanço do capitalismo no campo, a terra cumpre a função de mercadoria ("terra de negócio", nos termos de José de Souza Martins). Desse modo, a questão da "propriedade" da terra no Brasil é complexa. Em termos legais, dispomos de muitas modalidades de posse, porém a realidade e a legislação são instâncias marcadas pela desigualdade.

$\mathrm{Na}$ base dos conflitos de terra no Brasil está o interesse capitalista da burguesia agrária pela exploração da grande riqueza natural existente nas terras ainda ocupadas por indígenas e os limites da força política e econômica das diferentes modalidades de trabalhadores do campo, entre eles os povos originários.

[...] o que se observa em relação à terra no Brasil é uma complexa realidade que envolve, de um lado, múltiplas formas de acesso coletivo e comunitário, 
e lutas pelo seu controle democrático, no que diz respeito a terras indígenas, quilombolas, tradicionalmente ocupadas ou ocupadas pelos movimentos sociais em luta pela Reforma Agrária; e, de outro, a reafirmação de formas monopolistas de controle da propriedade da terra no Brasil, favorecidas por ações das diversas esferas do Estado brasileiro, seja quando nega a titulação de terras indígenas, rejeita o reconhecimento de terras quilombolas e não legitima terras tradicionalmente ocupadas, seja quando não desapropria para fins de Reforma Agrária as terras que descumprem a função social, favorece a grilagem de terras, garante a manutenção de latifúndios improdutivos intocados e preserva o direito de propriedade de quem utiliza mão de obra escrava. (Caldart et al. 2012, p. 444)

A questão da disputa de terras e o monopólio da posse nas mãos de classes economicamente poderosas são os principais impasses vividos pelas populações originárias que residem em regiões ricas em recursos naturais, especialmente quando essa classe dominante se encontra bem representada em uma bancada ruralista no Parlamento brasileiro e em aparelhos privados de hegemonia que atuam para legitimar os interesses dos "reis do agronegócio".

De acordo com o Relatório da Comissão Pastoral da Terra sobre os casos de violência no campo:

Em 2015, 50 pessoas foram assassinadas no campo, o maior número de vítimas desde 2004, e $39 \%$ a mais do que em 2014, quando foram registrados 36 assassinatos. Como em anos anteriores, a violência se concentrou de forma, pode-se dizer espantosa, na Amazônia, onde foram computados 47 dos 50 assassinatos — 20 em Rondônia, 19 no Pará, 6 no Maranhão, 1 no Amazonas, 1 no Mato Grosso - ; 30 das 59 tentativas de assassinato; 93 das 144 pessoas que receberam ameaças de morte; 66 dos 80 camponeses presos. E ainda 20.000.853 dos 21.374.544 hectares em conflito. 527 dos 998 conflitos por terra também lá ocorreram, com destaque para o Maranhão com 120, 99 no Pará e 83 em Rondônia. (CPT, 2015, p. 9-10)

Como verificamos no relatório, há uma condição alarmante de ameaças vividas pelos trabalhadores do campo. São números expressivos que indicam 
os interesses e as disputas pela riqueza dos recursos naturais disponíveis nas mãos da classe trabalhadora. Ainda de acordo com o relatório da Comissão:

\begin{abstract}
A mineração, as hidrelétricas e as madeireiras se expandem exigindo do poder público a construção de linhões, portos, o asfaltamento e abertura de estradas e de hidrovias e, consequentemente, a valorização das terras. Está pronto o caldo para o aumento e o acirramento dos conflitos e, sobretudo, para o crescimento da concentração da propriedade latifundiária. (CPT, 2015, p. 10)
\end{abstract}

O incessante interesse do grande capital continua a ameaçar as vidas dos povos das florestas, ribeirinhos, pesqueiros, quilombolas e indígenas que vivem uma relação com a terra-natureza não mercadológica. O processo de acumulação e renovação das formas de exploração do capital requer processos ampliados de expropriação. ${ }^{3}$ Essa lógica de exploração capitalista se depara com a resistência dos trabalhadores e lideranças organizados(as) do campo, usa da violência física, patrimonial e institucional para garantir a apropriação injusta e desigual da terra.

No início do século XIX, ocorrem diversas transformações no Brasil, especialmente a ruptura com o pacto colonial, superando o estado jurídico-político, nas palavras de Florestan Fernandes. Essa ruptura com o passado colonial não ocorre com a condição material que, para Fernandes (2005, p. 51), "iria perpetuar-se e servir de suporte à construção de uma nova sociedade nacional". ${ }^{4}$

3. Ao analisar a tendência incontrolável de expansão do capital, Virgínia Fontes (2010, p. 22) afirma que "a expropriação massiva é, portanto a condição inicial, meio e resultado da exploração capitalista". A autora continua: "[...] expandir as relações capitalistas corresponde, portanto, em primeiro lugar, à expansão das condições que exasperam a disponibilidade de trabalhadores para o capital, independentemente da forma jurídica que venha a recobrir a atividade laboral de tais seres sociais. A expropriação primária, original de grandes massas campesinas ou agrárias, convertidas de boa vontade (atraídas pelas cidades) ou não (expulsas, por razões diversas de suas terras, ou incapacitadas de manter sua reprodução plena através de procedimentos tradicionais, em geral, agrários) permanece e se aprofunda, ao lado de expropriações secundárias, impulsionadas pelo capitalismo - imperialismo contemporâneo [...]" (p. 44).

4. Com a independência do Brasil e a formação de um Estado nacional e as exigências de adaptação às mudanças políticas e econômicas internacionais, nascem os ideais de unidade e nacionalidade voltadas para 
Prevaleceu nesse período uma subalternidade ideológica da vida e das necessidades dos índios. Eram tratados como crianças órfãs, definindo a condição de tutela que juridicamente foi reafirmada no Código Penal de 1916, considerados como "menores de idade" e "relativamente incapazes", mantendo o princípio da tutela (Idem, p. 89 e 137). ${ }^{5}$

\subsection{A questão da terra na política indigenista no século XX}

No início do século XX, a questão indígena não era tratada substancialmente como se fosse social ou política. Estava situada nos conflitos de interesse econômico em torno da posse de terras. A Constituição de 1891 não tratava de forma substancial da questão, fazendo apenas breve menção a um possível reconhecimento de terras que eventualmente tivessem sido reconhecidas anteriormente pela Coroa portuguesa. Índios continuavam sendo vistos como problema para o desenvolvimento nacional e como obstáculo para o progresso nacional.

Após denúncias internacionais da condição indígena e dos trabalhadores do campo brasileiro, foi criado, em 1910, o Serviço de Proteção aos Índios e Localização de Trabalhadores Nacionais (SPILTN), que em 1918 se tornaria o Serviço de Proteção aos Índios, o SPI. Em função das dificuldades da primeira versão do órgão para atuar na amplitude das demandas de tantos grupos sociais, o SPI passa a atuar exclusivamente com as demandas indigenistas. O índio passa a ser visto como "um ser digno de conviver em comunhão

\footnotetext{
a construção de uma "única identidade histórica e cultural". A identidade indígena não era, nem de longe, aquela que representaria essa imagem nacional.

5. É importante enfatizar o papel que cumpriu a Lei de Terras de 1850, que dava o direito de posse da terra apenas àqueles que pagassem por ela. A lei excluía radicalmente pequenos lavradores e aldeias indígenas. No período, a política indigenista passa a ser da responsabilidade do Ministério da Agricultura, criado em 1860, sendo que diversas aldeias foram extintas formalmente e índios dispersados. "Seus habitantes são condenados a viver como posseiros sem terra, perdendo suas características específicas. O período do Brasil Império caracterizou-se com a afirmação do poder dos grandes senhores, do latifúndio, pela manutenção da servidão e da escravatura", afirma Gomes (2012, p. 88).
} 
nacional", mas permanece a visão da inferioridade cultural e "evolutiva". Vistos como infantis, "necessitariam da tutela do Estado a quem caberia dar-lhes condições para evoluir a um estágio cultural e econômico superior, para daí se integrarem à nação" (Gomes, 2012, p. 92-93).

No decorrer do século XX ocorreram muitas transformações positivas sobre a questão indígena brasileira, tanto na dimensão institucional de organização dos serviços de regularização das políticas como na atuação direta do Estado e dos órgãos de proteção em favor do avanço na legislação de proteção. Embora com elementos e instrumentos contraditórios, houve processos de mapeamento que favoreceram a visibilidade da presença indígena no território brasileiro, bem como, ainda que de forma limitada, a organização de dados e registros oficiais que dimensionaram a condição concreta da realidade dos povos.

Em 1928, é aprovada a Lei n. 5.484, que passa a regulamentar a situação jurídica dos índios. Exonera a tutela orfanológica e coloca-os sob a tutela do Estado. Ocorre o processo de "classificação" indígena de acordo com o grau de relacionamento com a sociedade brasileira, denominados como: "grupos nômades", "aldeados ou arrancados", "incorporados a centros agrícolas", e reunidos em povoações indígenas. Índios incorporados à sociedade ou em centros agrícolas são responsáveis por seus atos. (Gomes, 2012, p. 95-96)

A Constituição de 1934 apresenta pela primeira vez na história brasileira, e ainda de forma pontual, um artigo referente favorável à não alienação de suas terras: “[...] será respeitada a posse de terras de silvícolas que nelas se achem permanentemente localizados, sendo-lhes, no entanto, vedado aliená-las" (Gomes, 2012, p. 96).

No tópico que segue são apresentadas as mudanças conceituais sobre terras indígenas no sistema normativo brasileiro. Essas mudanças ocorrem a partir da ampliação da organização política de órgãos de defesa e alargamento da formação política e organização dos próprios indígenas. 


\section{A questão do direito indígena à terra no sistema normativo brasileiro}

Antes das décadas de 1970-1980 foram se ampliando e reafirmando leis voltadas para a definição e proteção das terras indígenas, mas ainda prevalecia a ideia integracionista de nacionalização e incorporação dos índios (essa era a meta principal do órgão indigenista). ${ }^{6}$

A Constituição de 1937, no artigo 154, definia: "Será respeitada aos silvícolas a posse das terras em que se achem localizados em caráter permanente, sendo-lhes, porém, vedada a alienação das mesmas". Nos termos da Constituição de 1946, artigo 216: "Será respeitada aos silvícolas a posse das terras onde se achem permanentemente localizados, com a condição de não se transferirem".

No decorrer do século XX modificam-se as definições formais por dentro da legislação do que são "terras indígenas", formas e tempo de "ocupação" (ocupação permanente, modo tradicional de ocupação, tempo de ocupação). Mudanças que passam a definir as ações do Estado brasileiro voltadas para a demarcação das terras indígenas e definição legal e institucional das formas de proteção, dos limites e controle dos territórios.

Gradativamente, amplia-se na sociedade brasileira o "sentimento de responsabilidade histórica do Estado brasileiro para com os índios" e o anseio de superar a condição de tutela e de objeto do Estado, construindo autonomia e atenção básica aos seus territórios. Esse sentimento entra em confronto com a nova realidade construída na trama do poder instituído pelo golpe militar de 1964.

Em meio aos retrocessos e violências próprias do regime militar que se instala no Brasil a partir de 1964, ocorrem diversas denúncias internacionais

6. O Decreto n. 736, de 6 de abril de 1936, estabelece que "os índios devem ser nacionalizados para serem incorporados à sociedade brasileira e define as terras indígenas como 'aquelas em que presentemente vivem e já primariamente habitavam e são necessárias para o meio de vida compatível com o seu estado social: caça, pesca, indústria extrativa, lavoura ou criação; aquelas que já lhes tenham sido ou venham ser reservadas para seu uso ou reconhecidas como de sua propriedade a qualquer título"' (Gomes, 2012, p. 96). 
das torturas e massacres realizados contra índios brasileiros, além de crimes de responsabilidade administrativa atribuídos ao SPI, situação que leva à extinção do órgão (Gomes, 2012, p. 100-101).

No cenário ideológico do "desenvolvimento com segurança" foi criada, em 5 de dezembro de 1967, a Fundação Nacional do Índio (Funai) com a missão precisa de transformar o índio em brasileiro, permitindo que "evoluísse" rapidamente: "[...] integrá-los à nação e assimilá-los culturalmente ao seu povo em um processo acelerado”, nas palavras de Gomes (2012).

Na conjuntura, a Constituição de 1967 trouxe mudanças e retrocessos jurídicos e políticos. Segundo Gomes (2012), na conceituação sobre terras indígenas que passam a ser da União e para os índios, restou a posse exclusiva e a inalienabilidade. No entanto, a nova definição favoreceu o processo de demarcação das terras indígenas.

Em 1973, foi aprovado o Estatuto do Índio, a Lei n. 6.001, de 19 de dezembro desse mesmo ano. ${ }^{7}$ A referida lei regulamenta aspectos jurídico-administrativos e determina a condição social e política do índio perante a nação, tratando da definição de terras indígenas e processos de regularização fundiária e estipulando medidas de assistência e promoção dos povos indígenas como indivíduos. ${ }^{8} \mathrm{O}$ Estatuto do Índio atribui à Funai a "responsabilidade de único agente responsável pela definição do que é terra indígena e pela demarcação em todas as 'etapas'. $\mathrm{O}$ ato final de homologação fica sob a prerrogativa do presidente da república" (Gomes, 2012). A Funai, como o principal órgão do Estado voltado para as demandas de proteção aos direitos indígenas, tem se tornado o centro das grandes tensões e investidas do pensamento conservador brasileiro que tenta ressuscitar as visões integracionistas e assimilacionistas sobre os povos indígenas.

7. De acordo com o Estatuto, "índio ou silvícola é todo indivíduo de origem e ascendência pré-colombiana que se identifica e é identificado como pertencente a um grupo étnico cujas características culturais o distinguem da sociedade nacional". E no seu art. 19: “As terras indígenas, por iniciativa e sob orientação do órgão federal de assistência ao índio, serão administrativamente demarcadas, de acordo com o processo estabelecido em decreto do Poder Executivo".

8. Gomes, 2012, p. 102. 


\subsection{A luta pela terra e afirmações constitucionais dos direitos indígenas no Brasil}

As décadas de 1970 e 1980 foram momentos marcantes em termos de espraiamento de retrocessos na interpretação da condição de vida dos povos indígenas e nas condições de trabalho do principal órgão de proteção, reconfigurado e enfraquecido pelo regime civil militar. Foi também um período de forte ebulição dos movimentos sociais na realidade brasileira, o que possibilitou denúncias e críticas sobre a atuação estatal. Naquele momento de redemocratização do país ocorreu uma ampliação dos debates sobre a "questão indígena" através da mobilização de organizações que defendiam as causas indígenas, como o Conselho Indigenista Missionário (Cimi) e da própria organização política crescente dos índios em favor dos seus direitos com a criação de associações indígenas em diversas partes do Brasil (Gomes, 2012, p. 109). O artigo 172, inciso IX, do Estatuto do Índio (1973), passa a afirmar:

Cumpre à União, aos estados e aos municípios, bem como aos órgãos das respectivas administrações indiretas, nos limites de sua competência, para a proteção das comunidades indígenas e a preservação dos seus direitos: garantir aos índios e comunidades indígenas, nos termos da Constituição, a posse permanente das terras que habitam, reconhecendo-lhes o direito ao usufruto exclusivo das riquezas naturais e de todas as utilidades naquelas terras existentes.

Com a abertura política no país e a força participativa dos movimentos em favor da Constituinte, a questão indígena passa a ganhar mais espaço na agenda política brasileira no sentido de reverter o quadro de retrocessos legais. De acordo com o documento do Conselho Federal de Serviço Social, o "CFESS Manifesta” de 2012, a questão indígena também ganha maior visibilidade em termos de avanços normativos pela significativa atuação do movimento indígena, que ganha força no período da redemocratização política do Brasil pós-1980. 
As reivindicações indígenas foram contempladas em grande parte na Constituição brasileira de 1988, concentradas no Capítulo VII, artigos 231 e 232. Legalmente, os/as índios/as são reconhecidos/as no seu modo de vida, quanto às suas formas de organização, costumes, línguas, crenças e tradições, e são assegurados os direitos originários sobre as terras tradicionalmente ocupadas por eles/as. Rompeu-se a perspectiva da integração desses povos à sociedade nacional. (CFESS, 2012, p. 2)

A Constituição federal apresenta mudanças significativas no que se refere à orientação da ação do Estado, reformulando os seus mecanismos de ações voltadas aos povos indígenas. ${ }^{9}$

Conforme Baniwa (2012), na década de 1970 emerge um movimento pan-indígena que ganhou ampla dimensão no continente latino-americano e conquistou direitos constitucionais nas décadas de 1980 e 1990 - defesa do direito à particularidade e à diversidade e denúncia das injustiças étnicas. No Brasil, com a aprovação da Constituição de 1988, a ideologia da unicidade do Estado se afirma como coisa do passado.

A Carta Magna mudou, em termos legais, significativamente a interpretação jurídico-social dos povos indígenas no país. Como afirma Baniwa, a Carta Magna supera a concepção de tutela, reconhecendo a capacidade civil dos índios; abandona o pressuposto integracionista, em favor do reconhecimento do direito à diferença sociocultural dos povos indígenas, na linha do multiculturalismo contemporâneo; reconhece a autonomia societária dos povos indígenas, garantindo para isso o direito ao território, à cultura, à educação, à saúde, ao desenvolvimento econômico, de acordo com seus projetos coletivos presentes e futuros; reconhece o direito à cidadania híbrida: étnica, nacional e global (Baniwa, 2012, p. 207).

A principal demanda da vida indígena, a terra, é apresentada como condição fundamental para a continuidade da vida e da saúde, a reprodução

9. No que se refere ao conceito de "terras indígenas", a CF de 1988, no parágrafo $1^{\circ}$ de seu artigo 231 define: "São terras tradicionalmente ocupadas pelos índios as por eles habitadas em caráter permanente, as utilizadas para suas atividades produtivas, as imprescindíveis à preservação dos recursos ambientais necessários a seu bem-estar e as necessárias a sua reprodução física e cultural, segundo seus usos, costumes e tradições". 
social, sua autodeterminação e seu etnodesenvolvimento. De acordo com a Constituição Federal de $1988,{ }^{10}$ nos termos da Funai (2016):

Terra Indígena (TI) é uma porção do território nacional, de propriedade da União, habitada por um ou mais povos indígenas, por ele(s) utilizada para suas atividades produtivas, imprescindível à preservação dos recursos ambientais necessários a seu bem-estar e necessária à sua reprodução física e cultural, segundo seus usos, costumes e tradições. Trata-se de um tipo específico de posse, de natureza originária e coletiva, que não se confunde com o conceito civilista de propriedade privada.

São mudanças significativas que possibilitam visualizar novos horizontes para os povos indígenas no enfrentamento cotidiano dos seus desafios diante da possibilidade do respeito à diferença e reais necessidades para sua continuidade humana e social.

No início deste século XXI, acompanhamos avanços nos debates sobre o fenômeno da "indianidade" e em favor da política da diferença.

Os povos indígenas têm direito à autodeterminação. Em virtude desse direito determinam livremente sua condição política e buscam livremente seu desenvolvimento econômico, social e cultural (Artigo 3) [...] Os povos e indivíduos indígenas têm direito a não sofrer assimilação forçada ou a destruição de sua cultura (Artigo 81). (Nações Unidas, $2008^{11}$ )

Entramos em um momento histórico de afirmação, no plano político, de uma nação pluriétnica, de rejeição das ideias evolucionistas, da busca pela garantia da legitimação de diferenças internas, garantias de direitos territoriais e repercussão desses avanços para as políticas indigenistas e indígenas (que possam envolver a participação efetiva dos povos em questão). Porém,

10. Ainda no parágrafo $\S 2^{\circ}$ : “As terras tradicionalmente ocupadas pelos índios destinam-se a sua posse permanente, cabendo-lhes o usufruto exclusivo das riquezas do solo, dos rios e dos lagos nelas existentes".

11. Declaração das Nações Unidas sobre os Direitos dos Povos Indígenas, 2008. 
esses avanços estão em confronto com a realidade da sociedade brasileira, como analisaremos no próximo tópico.

\subsection{Direitos humanos dos povos indígenas: as contradições do fenômeno jurídico na sociabilidade burguesa}

A realidade contemporânea e as demandas vitais próprias dos povos originários são muito complexas e dinâmicas. Um sistema jurídico normativo não dá conta de incorporar as demandas das diversas formas de organização social. Porém os povos indígenas e sua singularidade estão sob as determinações dessa dimensão da vida: o fenômeno jurídico da sociabilidade burguesa e suas formas de controle e regulação da vida social.

Tratar do "direito à terra" e da necessidade da demarcação das terras indígenas frente às ameaças da apropriação capitalista do campo é tratar do desenvolvimento concreto da singularidade indígena e sua interlocução com o complexo social total: como um ser social.

As populações originárias nativas foram engolidas (e dizimadas) durante todo o período colonial pela imposição de um novo sistema de vida. A própria construção de uma identidade nacional, de um poder estatal na realidade brasileira, coloca os indígenas numa condição radicalmente periférica, subalterna, para obedecer e se enquadrar efetivamente no sistema de normas que se refere à sua própria vida.

Neste tópico, não é possível dar conta da complexidade da análise sobre o direito por dentro das contradições do sistema jurídico capitalista burguês. Há uma tentativa de breves aproximações sobre a luta, na sociedade de classes, para garantia dos direitos básicos para a preservação da vida indígena.

De acordo com Sartori (nos seus estudos lukacsianos), o direito como sistema de normatividade contém uma essência classista. Envolve mediações de classes sociais, linguagem, divisão do trabalho e cotidiano. Nesse caso, para Sartori, o domínio de uma classe sobre a outra, como processo contraditório, nunca pode ser total. Significa dizer que a própria dinâmica 
social permite, em circunstâncias favoráveis, mudanças que respondam aos interesses das classes não dominantes, atendendo a interesses particulares. Desse modo, "o direito é uma mediação que se interpõe entre o domínio direto e os conflitos entre as diversas classes sociais com interesses diversos" (Sartori, 2010, p. 80).

Ainda conforme Sartori, o direito como fenômeno jurídico atua a partir de uma função homogeneizadora: "a vontade da lei, aparentemente unitária, surge de compromissos entre atores cuja função é contraditória nos conflitos oriundos da sociedade civil-burguesa”. Sartori, citando Lukács afirma: "[...] quanto mais a vida social se faz social, tanto mais nítida se torna tal homogeneidade" (2010, p. 80). E continua:

O Direito visa alcançar o maior número possível de condutas [...] e é inerente à sua forma buscar a totalidade da sociedade, colocando sobre o mesmo conjunto de normas os diversos indivíduos singulares [...] a própria legalidade da sociedade civil-burguesa, pois não deixa de ser uma imposição que avilta a personalidade dos indivíduos e tenta reprimir a mediação da particularidade, a qual se interpõe entre o singular e o universal. (p. 81).

Ao afirmar que "a totalização homogeneizante do fenômeno jurídico não é uma mera ilusão”, Sartori (2010) apresenta indicativos interessantes para refletir sobre a importância da luta indígena no seio contraditório da sociabilidade capitalista. É uma luta constante em favor da proteção de subsistemas diferenciados de organização da vida social e reprodução humana, como o caso da resistência das populações indígenas ribeirinhas, pesqueiras, que vivem artesanalmente dos recursos naturais da mata para garantir sua reprodução social. Como nos lembra Sartori (2010, p. 82):

O próprio complexo que prima pelos valores individualistas, em seu desenvolvimento real, subsume o indivíduo a uma categoria geral e niveladora [...] o indivíduo singular, assim, é colocado frente às normas universais de maneira abrupta; o que gera uma contradição que marca a forma de sociabilidade inerente à sociedade civil-burguesa. 
Para Sartori, $o$ fenômeno jurídico, porém, continua ligado à dominação de uma classe social exercida, sempre que preciso, por meio da violência. O direito, assim, se configura como uma mediação que atenua a dominação direta, mesmo a pressupondo, mantendo.

Dando continuidade à análise do direito como complexo contraditório, também contamos com a contribuição de Mészáros para a interpretação marxista dos problemas da "esfera legal”. O texto do autor dá atenção à concepção de direitos humanos, seus limites e possibilidades.

A recuperação da trajetória histórica das mudanças legais dos direitos indígenas no decorrer da história do Brasil apresentadas neste artigo não propõe uma visão legalista do tema. Como afirma Mészáros (2008, p. 162), "nada se resolve apenas pela proclamação de direitos, nem mesmo pelo mais solene dos direitos do homem. A esfera legal se torna eficaz na medida em que se introduz profundamente no corpo da 'sociedade civil'". Prossegue o autor (p. 163):

A “ilusão jurídica" é uma ilusão não porque afirma o impacto das ideias legais
sobre os processos materiais, mas porque o faz ignorando as mediações ma-
teriais necessárias que tornam esse impacto totalmente possível. As leis não
emanam simplesmente da "vontade livre dos indivíduos", mas do processo
total da vida e das realidades institucionais do desenvolvimento social dinâmi-
co, dos quais as determinações volitivas dos indivíduos são parte integrante.

As leis contemporâneas voltadas à proteção das demandas e necessidades próprias dos povos indígenas são resultado de muita luta, organização dos próprios indígenas e articulação com os órgãos que atuam em sua defesa. Também estão constantemente ameaçados porque entram em confronto com os processos materiais, com a realidade econômica dos empreendimentos capitalistas de exploração dos recursos naturais que ainda estão nas mãos dos povos originários. Essa tensão atinge toda a classe trabalhadora porque ela se volta contra os trabalhadores do campo, contra as próprias formas de vida marcadas pela produção e reprodução da vida em conexões diretas com a natureza. 
Não haverá emancipação humana dos povos indígenas por dentro do sistema capitalista, nem por dentro da divisão entre trabalhadores do campo, rurais e povos originários porque a massa de trabalhadores expropriados compõe toda a classe trabalhadora.

Como lembra Mészáros (2008, p. 168):

“[...] enquanto estivermos onde estamos, e enquanto o 'livre desenvolvimento das individualidades' estiver tão distante de nós como está, a realização dos direitos humanos é e permanece uma questão de alta relevância para todos os socialistas".

\section{Considerações finais}

A situação contemporânea dos processos de demarcação das terras indígenas encontra-se no centro de grandes ameaças e pressões da bancada ruralista no Congresso Nacional brasileiro. Além das propostas e investidas relacionadas à reestruturação da Funai (sucateamento, terceirizações, nomeações de militares para presidência), persistem propostas de mudanças significativas nos processos de demarcação de terra e códigos que regulamentam a exploração de recursos naturais no território brasileiro por parlamentares conservadores da direita representantes do agronegócio. É o caso das propostas de leis que tramitam no Congresso Nacional que visam extinguir direitos indígenas já conquistados, ou "modificar (dificultar) e criar possibilidades para a exploração dessas áreas por não indígenas" (ISA, 2016). ${ }^{12}$

Atualmente existem 462 terras indígenas regularizadas que representam cerca de $12,2 \%$ do território nacional, localizadas em todos os biomas, com concentração na Amazônia Legal (distribuídas da seguinte forma: 10\% no

12. Podemos destacar: "[...] a retirada do Poder Executivo, a função de agente demarcador das terras indígenas ao incluir entre as competências exclusivas do Congresso Nacional a aprovação de demarcação das terras tradicionalmente ocupadas pelos indígenas e a ratificação das demarcações já homologadas. Deputados e senadores teriam o poder, inclusive, de rever e reverter demarcações antigas ou já encerradas" (ISA, 2010). 
Sul, 6\% no Sudeste, $54 \%$ no Norte, $11 \%$ no Nordeste, e $19 \%$ no Centro-Oeste do país) (Funai, 2016). A demarcação das terras indígenas é muito importante, pois possibilita para os indígenas a segurança de um espaço fundiário que lhes assegure meios dignos de subsistência econômica, como prevê a legislação.

As condições de continuidade da vida indígena envolvem uma lista infindável de ameaças, tanto para os povos que vivem nas florestas como para os que vivem na caatinga sertaneja, dos ribeirinhos do sertão aos litorâneos, que passam a assumir vida de migrantes, adentrando nas filas do proletariado urbano ou nos bolsões de pobreza das grandes cidades.

Documentos como "O dossiê Belo Monte - Não há condições para a licença de operação”, organizado pelo Instituto Socioambiental (ISA) e publicado em junho de 2015 (que denuncia os riscos para as populações indígenas ribeirinhas com o início do enchimento dos reservatórios da usina hidrelétrica de Belo Monte, situada na região de Altamira, PA e com o desvio definitivo do rio Xingu para que parte da usina comece a operar) e o relatório "Violência contra os povos indígenas no Brasil — dados de 2015”, elaborado pelo Conselho Indigenista Missionário, são reveladores das condições aviltantes impostas aos povos indígenas brasileiros. ${ }^{13}$

Embora reconheçamos a impossibilidade da norma, de a lei transformar a vida concreta, por reconhecer os limites da igualdade formal, e da função social do sistema jurídico na sociedade capitalista, é importante destacar o avanço normativo que trata dos direitos dos povos indígenas no Brasil. A aceitação social de que as terras indígenas são "direitos originários", ou seja, antecedem a criação do próprio Estado brasileiro, é fundamental para

13. O relatório do Cimi (2015) apresenta dados nacionais sobre as diversas formas de violência sofridas pelos povos indígenas brasileiros: violência contra o Patrimônio (omissão e morosidade na regularização de terras, conflitos relativos a direitos territoriais, invasões possessórias, exploração ilegal de recursos naturais e danos diversos ao patrimônio); violência contra a pessoa (assassinatos, tentativa de assassinato, homicídio culposo, ameaça de morte, lesões corporais dolosas, abuso de poder, racismo e discriminação étnico cultural, violência); violência por omissão do Poder Público (suicídio, desassistência na área de saúde, morte por desassistência à saúde; mortalidade infantil, disseminação de bebida alcoólica e outras drogas, desassistência na área de educação escolar indígena; desassistência geral). 
os processos de demarcação, considerando as pressões constantes do grande capital através do agronegócio que amplia os processos de expropriação dos povos indígenas de suas terras.

Enquanto vivemos sob as determinações do sistema capitalista, as conquistas políticas e constitucionais dos povos originários ainda atuarão de forma significativa para garantir estratégias de proteção da vida dos nossos povos.

Recebido em 15/4/17 - Aprovado em 27/2/18

\section{Referências bibliográficas}

ALMEIDA, Maria Celestino de. Os índios na história do Brasil. Rio de Janeiro: Editora FGV, 2010.

BANIWA, Gersem. A conquista da cidadania indígena e o fantasma da tutela no Brasil contemporâneo. In: RAMOS, Alcida Rita. Constituições nacionais e povos indígenas. Belo Horizonte: Editora UFMG, 2012.

BRASIL. Lei n. 6.001, de 19 de dezembro de 1973. Dispõe sobre o Estatuto do Índio.

CALDART, Roseli Salete et al. (Orgs.). Dicionário da educação do campo. Rio de Janeiro: Escola Politécnica de Saúde Joaquim Venâncio, São Paulo: Expressão Popular, 2012.

CFESS. CFESS Manifesta: Dia da luta indígena. Conselho Federal de Serviço Social. Gestão Tempo de Luta e Resistência. Brasília, 19 abr. 2012. Disponível em: <http:// www.cfess.org.br>. Acesso em: set. 2016.

CIMI - CONSELHO INDIGENISTA MISSIONÁRIO. Violência contra os povos indígenas no Brasil - dados de 2015. Disponível em: <http://www.cimi.org.br/pub/ relatorio2015/relatoriodados2015.pdf>. Acesso em: set. 2016.

CPT - COMISSÃO PASTORAL DA TERRA. Conflitos no campo - Brasil 2015. Goiânia: CPT Nacional, 2015.

FONTES, Virgínia. Brasil e o capital imperialismo: teoria e história. 2. ed. Rio de Janeiro: EPSJV/Editora UFRJ, 2010. 
FERNANDES, Florestan. A revolução burguesa no Brasil: ensaio de interpretação sociológica. 5. ed. São Paulo: Globo, 2005.

FUNAI - FUNDAÇÃO NACIONAL DO ÍNDIO. Politica Indigenista, 2016. Disponível em: <http://www.funai.gov.br/>. Acesso em: set. 2016.

GOMES, Mércio Pereira. Os índios e o Brasil: passado, presente e futuro. São Paulo: Contexto, 2012.

ISA - INSTITUTO SOCIOAMBIENTAL. Terras indígenas: ameaças, conflitos e polêmicas. Disponível em: <https://pib.socioambiental.org>. Acesso em: nov. 2016.

MÉSZÁROS, I. Filosofia, ideologia e ciências sociais. Trad. Ester Vaiman. São Paulo: Boitempo, 2008.

NAÇÕES UNIDAS. Declaração das Nações Unidas sobre os direitos dos povos indígenas. Rio de Janeiro: Nações Unidas, 2008. Disponível em: <http://www.un.org/ esa/socdev/unpfii/documents/DRIPS_pt.pdf $>$. Acesso em: nov. 2016.

SARTORI, Vitor S. Crítica ontológica ao direito. São Paulo: Cortez, 2010.

\section{Nota da autora}

Elizângela Cardoso de Araújo Silva - Assistente social, doutoranda em Serviço Social (PPGSS/UFPE), membro do Núcleo de Estudos e Pesquisas sobre Questão Ambiental e Serviço Social (Nepass/UFPE). E-mail: elicardosoaraujo17@gmail.com 